\title{
Renewal of cue-elicited urge to smoke: implications for cue exposure treatment
}

Citation for published version (APA):

Thewissen, R., Snijders, S. J. B. D., Havermans, R. C., van den Hout, M. A., \& Jansen, A. T. M. (2006). Renewal of cue-elicited urge to smoke: implications for cue exposure treatment. Behaviour Research and Therapy, 44(10), 1441-1449. https://doi.org/10.1016/j.brat.2005.10.010

Document status and date:

Published: 01/01/2006

DOI:

10.1016/j.brat.2005.10.010

Document Version:

Publisher's PDF, also known as Version of record

Document license:

Taverne

Please check the document version of this publication:

- A submitted manuscript is the version of the article upon submission and before peer-review. There can be important differences between the submitted version and the official published version of record.

People interested in the research are advised to contact the author for the final version of the publication, or visit the DOI to the publisher's website.

- The final author version and the galley proof are versions of the publication after peer review.

- The final published version features the final layout of the paper including the volume, issue and page numbers.

Link to publication

\footnotetext{
General rights rights.

- You may freely distribute the URL identifying the publication in the public portal. please follow below link for the End User Agreement:

www.umlib.nl/taverne-license

Take down policy

If you believe that this document breaches copyright please contact us at:

repository@maastrichtuniversity.nl

providing details and we will investigate your claim.
}

Copyright and moral rights for the publications made accessible in the public portal are retained by the authors and/or other copyright owners and it is a condition of accessing publications that users recognise and abide by the legal requirements associated with these

- Users may download and print one copy of any publication from the public portal for the purpose of private study or research.

- You may not further distribute the material or use it for any profit-making activity or commercial gain

If the publication is distributed under the terms of Article $25 \mathrm{fa}$ of the Dutch Copyright Act, indicated by the "Taverne" license above, 


\title{
Renewal of cue-elicited urge to smoke: Implications for cue exposure treatment
}

\author{
Roy Thewissen ${ }^{\mathrm{a}, \mathrm{b}, *}$, Steffie J.B.D. Snijders ${ }^{\mathrm{b}}$, Remco C. Havermans ${ }^{\mathrm{b}}$, \\ Marcel van den Hout ${ }^{\mathrm{c}}$, Anita Jansen ${ }^{\mathrm{b}}$ \\ ${ }^{a}$ Department of Medical, Clinical and Experimental Psychology, Maastricht University, P.O. Box 616, 6200 MD Maastricht, \\ The Netherlands \\ ${ }^{\mathrm{b}}$ Faculty of Psychology, Department of Experimental Psychology, Maastricht University, P.O. Box 616, 6200 MD Maastricht, \\ The Netherlands \\ ${ }^{\mathrm{c}}$ Department of Clinical Psychology, Utrecht University, The Netherlands
}

Received 10 March 2005; received in revised form 4 October 2005; accepted 14 October 2005

\begin{abstract}
The effects of cue exposure therapy are limited, because renewal after extinction is an important source of relapse. In this study, 33 smokers were exposed to a cue predicting smoking availability and a cue predicting smoking unavailability in one context (acquisition context A). Following extinction in another context (extinction context B), a test for renewal took place in the original acquisition context A (i.e. ABA renewal). Urge to smoke was measured using a Visual Analogue Scale. Renewal of differential conditioned urge responding occurred when participants were tested in the acquisition context, while differential urge responding remained extinguished when tested in the extinction context. This experiment provides evidence that ABA renewal occurred in smokers. Clinical implications are discussed.
\end{abstract}

(C) 2005 Elsevier Ltd. All rights reserved.

Keywords: Context; Cue exposure; Renewal; Smoking urges

\section{Introduction}

Exposure-based therapies are based on Pavlovian conditioning principles and are widely practiced in the treatment of a variety of psychopathology such as anxiety disorders, eating disorders as well as addictive behaviours (e.g. Öst, 1997; Jansen, 1998; Drummond, Tiffany, Glautier, \& Remington, 1995). Cue exposure with response prevention was developed to reduce the urge to use a drug (Brandon, Piasecki, Quinn, \& Baker, 1995). In case of smoking addiction, a smoker is repeatedly exposed to smoking cues (e.g. cigarettes, lighters, ashtrays), but is not allowed to smoke (response prevention). This procedure then should lead to the elimination of the previously learned association between smoking-related cues (conditioned stimuli, CSs) and

\footnotetext{
*Corresponding author. Faculty of Psychology, Department of Experimental Psychology, Maastricht University, P.O. Box 616, 6200 MD Maastricht, The Netherlands. Tel.: + 31433882476.

E-mail address: r.thewissen@psychology.unimaas.nl (R. Thewissen).
} 
the intake of smoke (unconditioned stimulus, US), because the smoking-related stimuli no longer predict smoke intake. As a result, cue-elicited urge to smoke (i.e., the conditioned response, CR) should be extinguished. Furthermore, by eliminating an important motivation for smoking the probability of a (re)lapse should be reduced.

Although outcome studies of cue exposure in the realm of addiction yielded some promising results, there is still room for improvement (Conklin \& Tiffany, 2002). More fundamental learning research has shed some light on the limitations of exposure-based treatments and suggested possible ways to overcome these limitations. During cue exposure, the individual is exposed to the CS (e.g. smoking cues) without the drug (US) being presented. Under these conditions, 'extinction' is held to occur. Traditionally, extinction is conceptualized as the unlearning of the association between CS and US. The work of Bouton (1988, 2000) however indicates that this is fundamentally incorrect. Extinction is not 'unlearning' the CS-US association, but instead learning that in the context in which extinction takes place the CS will not be followed by a US. Strong support for this position is the fact that extinguished conditioned responding is 'renewed' when the CS is presented in a context other than the extinction context.

For addiction, some evidence for renewal has been found within heavy drinkers. Collins and Brandon (2002) conducted a clinical analogue experiment with moderate to heavy social drinkers and found a significant renewal of extinguished alcohol cue reactivity. Recently, fundamental research into human learning mechanisms done by Vansteenwegen et al. (2005) found evidence for renewal using a differential fear conditioning paradigm (see also Havermans, Keuker, Lataster, \& Jansen, 2005).

Renewal may thus contribute to the limited effect of cue exposure in the treatment of addiction. However, in the studies described above, it is assumed that cue-elicited urges are the result of prior conditioning. This is not necessarily the case. Field and Duka (2001) for instance argue that cue reactivity measured in the laboratory could reflect non-specific arousal or might be due to perceived demands of the experiment. An obvious advantage of clinical analogue experiments is the control one has over the learning phases of acquisition and extinction. Collins and Brandon (2002) for example did not have any control over the acquisition of cue reactivity of their participants and the context in which acquisition could have taken place. Therefore, the present experiment was specially designed to establish such control. The experimental procedure used in this experiment was similar to the procedure used by Thewissen, Van den Hout, Havermans, and Jansen (2005) and was a discriminative classical conditioning task in which 'cue-availability' (Carter \& Tiffany, 2001) or 'perceived drug use opportunity' (Wertz \& Sayette, 2001) was manipulated; that is, participants were exposed to their smoking cues following either an availability or an unavailability cue (signalled by a blue versus a yellow serving tray). After smoking cues were presented with the availability cue participants were instructed to smoke, but when presented with the unavailability cue they had to refrain from smoking. The primary aim of the present study was to investigate whether an association between cue and smoking acquired in a context A can be extinguished in another context $\mathrm{B}$ and if so, whether extinguished urge responding can be renewed when presented with the cue in context A (i.e. ABA renewal).

\section{Method}

\section{Participants}

Thirty-three smokers ( 8 males, 25 females; $M$ age $=21.3$ years; SD = 1.72) who smoked a minimum of five cigarettes a day for at least 2 years were recruited at Maastricht University. All participants completed the Fagerström test for nicotine dependence (FTND; Heatherton, Kozlowski, Frecker, \& Fagerström, 1991). The average score on the FTND was $2.70(\mathrm{SD}=2.07)$, which indicates that participants, on average, had a low level of 'nicotine dependence'. Fourteen participants smoked less than 10 cigarettes a day, 14 participants smoked between 11 and 20 cigarettes a day, four participants smoked between 21 and 30 cigarettes a day and one participant smoked more than 30 cigarettes a day. Participants had to abstain from smoking for $2 \mathrm{~h}$ prior to the experiment. An abstinence period of $2 \mathrm{~h}$ was chosen to avoid floor or ceiling effects of urge during the conditioning task. 


\section{Independent variables}

Smoking cues: The smoking cues were stimuli presumed to elicit conditioned urge responses as a result of smoking history. The participant's favourite brand of cigarettes, a lighter, and an ashtray were used as smoking cues.

Availability cues: A blue or a yellow colour of a serving tray signalled the occurrence or non-occurrence of smoking. For half of the participants, a blue serving tray indicated that smoking - after presentation of the smoking cues - was allowed, and a yellow serving tray indicated that smoking was not allowed. For the other half, the meaning of the colours of the serving trays was reversed. These availability cues served as CSs respectively predicting the occurrence of smoking $(\mathrm{CS}+)$ and absence of smoking $(\mathrm{CS}-$ ). The US consisted of one puff of a cigarette.

Contexts: Two rooms (an 'office' and a 'therapy room') represented contexts that differed on their physical characteristics, but both had low smoke-relevant characteristics. The 'office' consisted of two desks, two computers, office materials (e.g. phones, pens, papers, and covers), a red carpet and red office chairs. The 'therapy room' had one desk, books, pens, writing papers, plants, 'nature posters', a flip-over, and blue chairs. Further, the 'office' had a window and 'After Tobacco Air' (Ambi Pur, Veenendaal/The Netherlands) was spread in this room, while the 'therapy room' had no window and had a 'Vanilla \& Lily' (Ambi Pur, Veenendaal/The Netherlands) odour. The 'office' and the 'therapy room' were located in two different department buildings at Maastricht University and both had a respiratory tube connected to a ventilator in the ceiling. The respiratory tubes in the 'office' and the 'therapy room' were of different material and colour.

\section{Dependent variables}

Smoke-relevant characteristics: In the pre-acquisition phase, in each room, $100 \mathrm{~mm}$ Visual Analogue Scales (VASs) were used to measure 'valence of the room' ("In this room, I feel": 0 "very unpleasant/negative"-100 "very pleasant/positive"), 'subjective arousal' ("In this room, I feel": 0 "very relaxed"-100 "very tense"), "urge to smoke' ("At this moment, I feel": 0 "no urge to smoke at all"-100 "an almost irresistible urge to smoke"), 'reference to a smoking context' ("This room makes me think of a room in which I smoked": 0 "very little to not at all"-100 "very much"), "perceived control of smoking' ("If at this moment I would be offered a cigarette, I would be": 0 "definitely not able to refuse"-100 "definitely able to refuse"), and "expectation of availability to smoke' ("In this room, in general, I expect to be allowed to smoke": 0 "definitely not" -100 "definitely"), respectively. These VASs were used to test the smoke-relevant characteristics of both contexts. Additionally, a $100 \mathrm{~mm}$ VAS ("The first room differs from the second room": 0 "to a small extent"-100 "to a large extent") was used to measure the extent to which subjects considered the two rooms as being physically different.

Urge to smoke: During the acquisition phase, as well as in the extinction phase and the test phase, $100 \mathrm{~mm}$ VASs ("At this moment, I feel": 0 "no urge to smoke at all"-100 "an almost irresistible urge to smoke") were used to measure urge to smoke.

\section{Procedure}

The experiment started with an introduction in which participants were told what the meaning was of the blue and the yellow serving tray (i.e., signalling smoking availability or unavailability). After this introduction, participants gave informed consent. In addition, participants completed a general smoking questionnaire and the FTND. All of this took place in a waiting room.

Pre-acquisition phase: Participants moved to the 'office' or the 'therapy-room' for a pre-acquisition session. After being seated at a desk, subjects were told to relax for $1 \mathrm{~min}$ while concentrating on the features of the room and taking notice of their feelings at that moment. Next, subjects rated 'valence of the room', 'subjective arousal', 'urge to smoke', 'reference to a smoking context', 'perceived control of smoking' and 'expectation of availability to smoke' on VASs. After this, subjects moved to the other context in which the same procedure was followed as in the first pre-acquisition session. In the second pre-acquisition session subjects completed the six VASs and an additional VAS that measured to what extent participants evaluated the two rooms as being 
physically different. Next, participants had a 5 min reading break and were escorted to the acquisition context that was the same context as the room in which the second pre-acquisition session had taken place (the 'office' or the 'therapy-room').

Acquisition phase: After being seated at a desk, participants were again instructed about the meaning of the blue and the yellow serving tray (i.e., signalling smoking availability or unavailability). The acquisition phase started with the presentation of a blue or a yellow serving tray for approximately $25 \mathrm{~s}$. Participants were instructed to concentrate on the serving tray and to focus on their urge to smoke, after which they rated their urge to smoke on a VAS. Next, a participant's favourite brand of cigarettes, a lighter and an ashtray were placed on the serving tray. Participants were instructed to take a cigarette out of the cigarette box and handle the cigarette (touch it, place it between their lips, holding it) without lighting the cigarette. After approximately $25 \mathrm{~s}$, subjects rated their urge to smoke on a second VAS. Following the second craving assessment, participants took one puff of a cigarette when the colour of the serving tray indicated that smoking was allowed and exhaled the smoke through a respiratory tube. If the colour of the serving tray indicated that smoking was not allowed, participants held the cigarette between their lips and a burning lighter next to it, but did not light the cigarette. After the occurrence or non-occurrence of smoking, subjects read for 3 min. Each participant completed six trials: three trials with a blue serving tray and three trials with a yellow serving tray in a random order with the restriction of no more than two consecutive trials of the same type. In total, the acquisition phase had a duration of approximately $30 \mathrm{~min}$. Following the last trial, participants were taken to the other room in which extinction would take place.

Extinction phase: The procedure for the extinction phase was the same as with the acquisition phase except smokers were not allowed to smoke at all. After being seated at a desk, participants were instructed about the new meaning of the blue and the yellow serving tray (i.e., both signalling smoking unavailability). Following the last trial, half the participants relaxed and read in a waiting room for $5 \mathrm{~min}$ and the other half was escorted to the other context.

Renewal test phase 1: In the first renewal test phase, participants were presented with a blue or a yellow serving tray, after which they completed a VAS of urge to smoke. Next, they were exposed to their smoking cues, followed by a second urge VAS. After a 3 min reading break, a serving tray of the other colour was presented to the subjects, followed by an urge VAS. After this, exposure to smoking cues occurred and a second urge VAS was completed. In both trials, participants were not allowed to smoke. After this, subjects moved to the other context (the 'office' or the 'therapy-room').

Renewal test phase 2: In the second renewal test phase, the same procedure was followed as in the first renewal test phase. The only difference between the two test phases was that they took place in two different contexts (counterbalanced). At the end of the second renewal test phase, participants were paid and debriefed in a waiting room.

\section{Results}

\section{Data reduction and analyses}

Results will be reported for the four main phases of the experiments: pre-acquisition, acquisition, extinction and test. For all analyses, a rejection criterion of .05 was used. Huynh-Feldt epsilon corrections and corresponding adjustments to the degrees of freedom are reported for all repeated measures analyses of variance (ANOVAs) in which the assumption of sphericity was violated.

\section{Pre-acquisition}

During the pre-acquisition phase self-report measures of 'perceived expectation of availability to smoke', 'reference to a smoking context', 'urge to smoke', 'control of smoking', 'valence of the room', and 'subjective arousal' were scored on a 100-mm VAS. This was done for the two rooms. Additionally, a 100-mm VAS was used to measure the extent to which participants evaluated the two rooms as being different. To test for renewed cue-elicited smoking urges, the contexts used in this experiment had to be physically different but 
equivalent on their smoke relevant characteristics; that is, both contexts had to produce the same response pattern on all the aforementioned measures.

The two contexts, 'office' context and 'therapy-room' context, were equal on all indices $(-.56<t<2.02$; $d f=32$; all $p>.05$ ), except on the measurement of 'valence of the room' $[t(32)=3.18 ; p<.001]$, indicating that the 'therapy-room' context was more positively labelled than the 'office' context. Further, participants evaluated these rooms as being distinct, $t(32)=28.16 ; p<.001$.

\section{Acquisition and extinction}

To be able to test for renewed cue-elicited urges to smoke, initial acquisition of cue-elicited urge responding and subsequent extinction of such responding had to be ascertained. The mean urges to smoke scores in all four conditions as measured during the acquisition phase are shown in Fig. 1.

During acquisition, extinction and test, every presentation of the coloured serving tray (availability cues) and every presentation of the smoking cues (cue) were followed by a 100-mm VAS (urge to smoke). During the acquisition and extinction phase, there were three trials of each availability or unavailability cue (yellow and blue serving tray) and during every trial, availability cues were presented alone and with smoking cues. Separate $2 \times 2 \times 3$ (smoking cue $\times$ availability cues $\times$ trial) within-subjects ANOVAs were performed for the acquisition and extinction phase.

For acquisition, the analyses confirmed that urges to smoke are higher given the availability cue than given the unavailability cue, $F(1,32)=28.41, p<.001$. Thus, the availability cues acquired the conditional potency to differentially elicit urge responding. The availability cue $(\mathrm{CS}+)$ associated with the occurrence of smoking behaviour (US) elicited higher urge responses (CR) than the unavailability cue (CS-) associated with the absence of smoking behaviour (no US), irrespective of the presentation of the smoking cues.

Further, a significant main effect of smoking cues was revealed, $F(1,32)=52.04, p<.001$. When exposed to their smoking cues participants reported higher urge scores than when not. The analyses also revealed a significant interaction effect of availability cues $\times$ smoking cue, $F(1,32)=4.17, p<.05$, and a significant availability cues $\times$ smoking cue $\times$ trial $[F(1.64,52.51)=3.53, p<.05]$ interaction. The latter three-way interaction indicates that the urge-inducing effects of smoking cues was larger given the unavailability cue than the availability cue, particularly on the first acquisition trial as can be inferred from Fig. 1.

No significant main effect of trial was revealed, $F(1.58,50.66)=1.25, n s$. However, there was a significant interaction between smoking cues and trial, $F(2,64)=15.41, p<.001$, indicating that the urge scores differed for the presence or absence of smoking cues over trials. As can be inferred from Fig. 1, the urge to smoke increased somewhat after the first trial in the absence of smoking cues, whereas in the presence of these smoking cues the urge to smoke remained relatively constant across the trials.

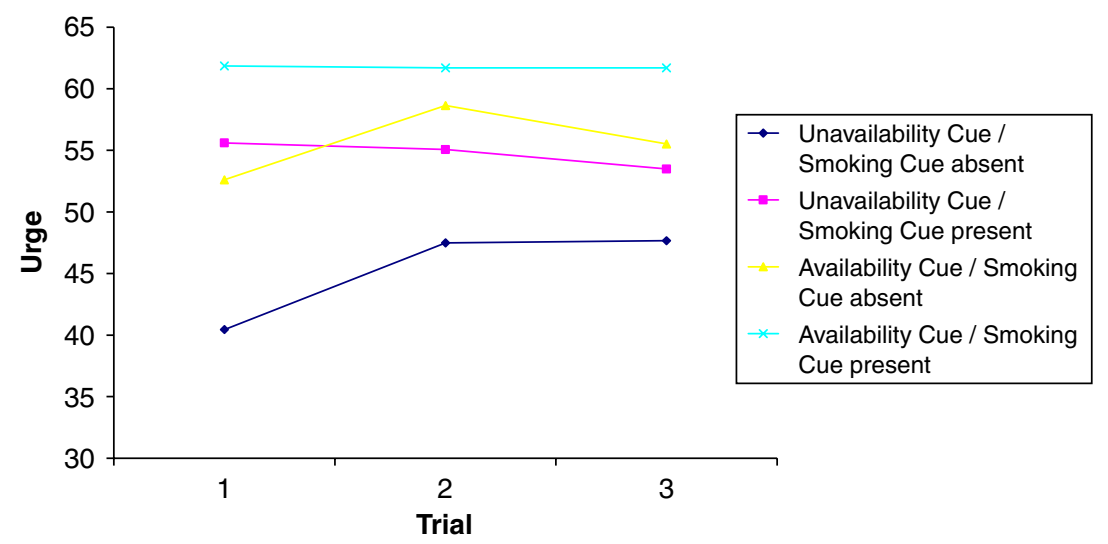

Fig. 1. Effect of availability cues and smoking cues on the urge to smoke at trial $1-3$ of the acquisition phase $(n=33)$. 


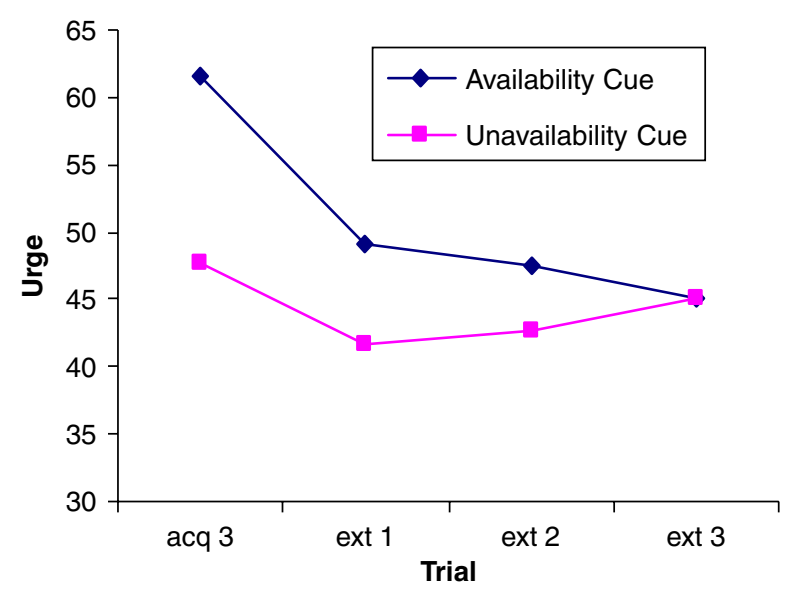

Fig. 2. Overall effect of availability cues on the urge to smoke as measured on the third and last acquisition trial (acq 3 ) and during the subsequent extinction phase (trials ext 1-3) for the participants who had shown successful acquisition of differential urge responding to the availability cues $(n=25)$.

Extinction (or renewal) can only take place if learning has occurred. For this reason the analyses of the extinction and renewal phase are presented for the 25 out of the 33 participants showing successful acquisition (i.e., differential urge responding to the availability cues).

The overall effect of availability cues on urge to smoke as measured on the last acquisition trial and during the subsequent extinction phase is depicted in Fig. 2.

The availability cues (availability versus unavailability) $\times$ smoking cues (present versus absent) $\times$ trial (extinction trials 1, 2, or 3) ANOVA revealed a significant main effect of availability cues, $F(1,24)=5.39$, $p<.05$, showing that on average urge to smoke was higher given the availability cue than given the unavailability cue. Moreover, an availability cues $\times$ trial interaction was found, $F(2,48)=4.89, p<.05$, demonstrating extinction of differential urge responding to the availability and the unavailability cue. Further post-hoc analyses revealed that for the availability cue there was a significant decrease in reported urge to smoke from the last acquisition trial to the last extinction trial, $F(2.33,55.93)=10.64, p<.01$, whereas urge responding to the unavailability cue did not increase significantly from the last acquisition trial to the last extinction trial, $F(2.46,58.98)=2.27$, $n s$. This implies that the loss of differential urge responding to the availability cues can be largely attributed to the decrease in the urge to smoke in the presence of the availability cue.

Further results indicated that smokers reported higher levels of urge to smoke when exposed to their smoking cues than when not, $F(1,24)=19.90, p<.001$. No main effect of trial was revealed by the analysis, $F(2,48)<1, n s$.

A significant interaction of availability cues $\times$ smoking cues, $F(1,24)=14.46, p<.01$, showed that the urge inducing effect of the smoking cues was larger given the unavailability than given the availability cue. No availability cues $\times$ smoking cues $\times$ trial interaction was revealed, $F(2,48)=2.70, n s$.

\section{Renewal test}

Since the results of the extinction phase clearly demonstrated an extinction of differential urge responding to the availability cues, in particular reflected by the decrease in urge to smoke in the presence of the availability cue, a test for renewal after a room context change was warranted. For the test phase, a $2 \times 2 \times 2$ (context change $\times$ availability cues $\times$ smoking cue) repeated measures ANOVA was performed.

Fig. 3 depicts the effect of a context change on differential urge responding to the availability cues during the test phase. The ANOVA revealed a significant main effect of context change, $F(1,24)=5.27, p<.05$, showing that urge to smoke is higher given a context change at test than when not. More specifically, a significant interaction effect of context change $\times$ availability cues, $F(1,24)=4.34, p<.05$, revealed that the 


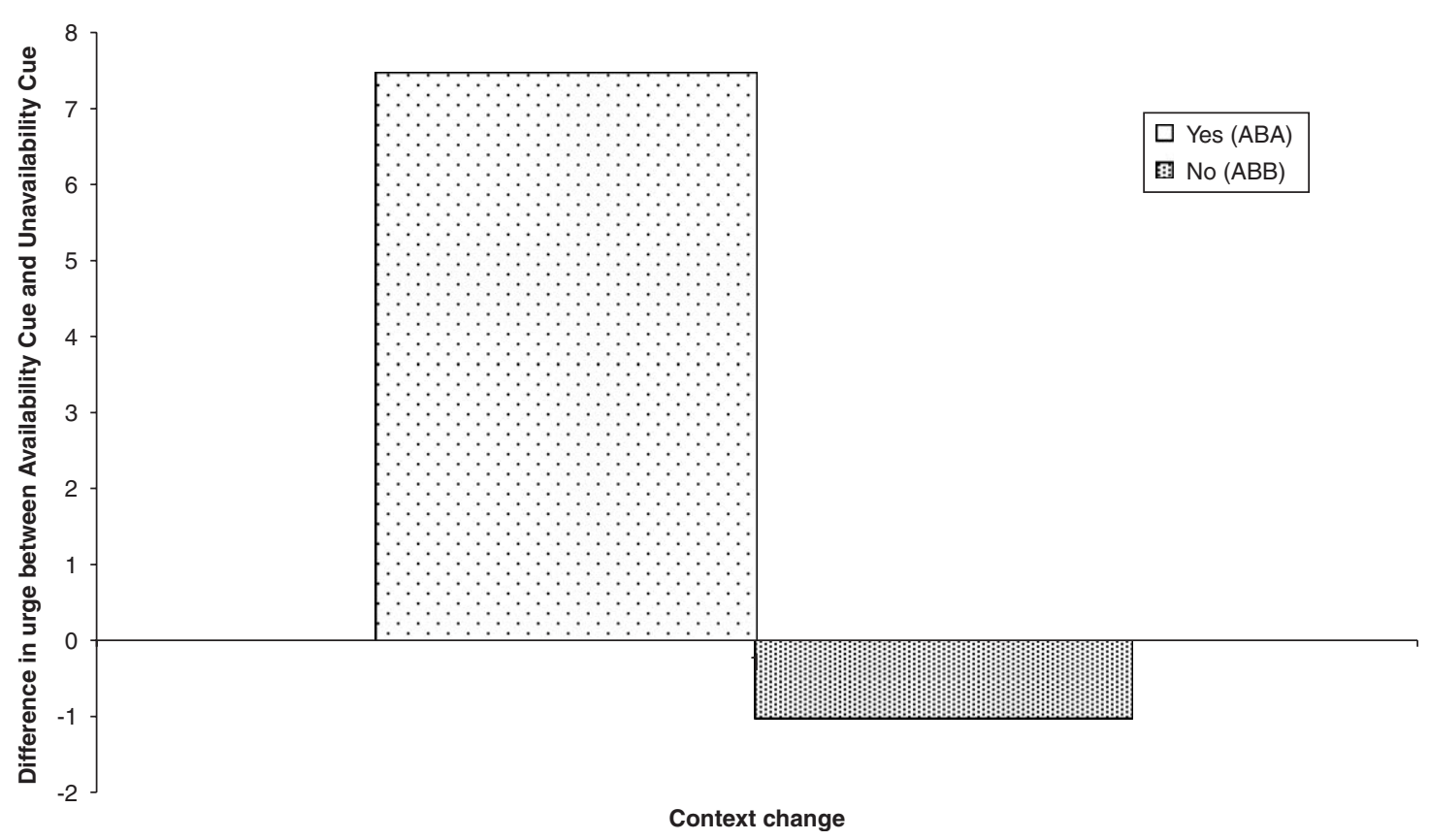

Fig. 3. Effect of a context change on differential urge responding to the availability cues at test. The $Y$-axis represents the mean difference in urge to smoke between the unavailability cue and the availability cue.

availability cue elicited more urge to smoke than the unavailability cue when the test occurred in the acquisition context (i.e. ABA renewal), than when tested in the extinction context (i.e. ABB control). Planned comparisons confirmed this renewal effect by revealing that the differential effect of availability cues was significant in case of a context change $[\mathrm{ABA} ; t(24)=3.03, p<.01]$, but not significant in case of no context change $[\mathrm{ABB} ; t(24)=.36, n s]$.

Further results revealed a significant main effect of smoking cue, $F(1,24)=16.16, p<.01$, again reflecting smokers reporting a higher urge to smoke when exposed to their smoking cues.

\section{Discussion}

It was hypothesized that extinguished cue-elicited urge to smoke can be renewed. The results clearly demonstrate renewal of extinguished differential urge responding to the availability cues when tested in the room context in which acquisition took place (ABA renewal). Apparently, extinguished cue-elicited urge to smoke is context-dependent and tends to be renewed when individuals find themselves outside the context where extinction treatment took place.

As the bulk of evidence regarding the phenomenon of renewal in human learning in general and specifically in human psychopathology grows, the call for improvement of exposure-based treatment strategies gets more and more pronounced (see Bouton, 2002; Conklin \& Tiffany, 2002; Havermans \& Jansen, 2003). In general, the results of this study points to the importance of the role of the broader context in which cue exposure takes place. In that respect it should be noted that following Marlatt and Gordon's (1985) theoretical framework of determinants of relapse of addictive behaviour, the two room contexts used in the present study can be defined as 'low risk situations' as opposed to 'high risk situations'. That is, these room contexts possess a relatively low risk for relapse because of their low smoke relevant characteristics. Therefore, it is conceivable that situational contexts with high smoking relevant characteristics hold a greater risk for relapse that would be evidenced by an even more pronounced renewal effect after a context change from a low smoke relevant treatment context to a high risk situation. Further research should illuminate this matter.

The results of the present study again replicate the main finding of the studies by Dols, Willems, Van den Hout, and Bittoun (2000), Dols, Van den Hout, Kindt, and Willems (2002) and Thewissen et al. (2005) that 
smokers report higher levels of urge to smoke when exposed to a cue signalling the availability of smoking than when exposed to a cue signalling the unavailability of smoking. Hence, the availability cues acquired the capacity to differentially elicit urge responding. Dols et al. (2002) state that cue reactivity does not necessarily depend on a long history of associative learning between smoking-related cues and smoking behaviour, but that the predictive value regarding the availability of smoking is crucial in evoking urge responses to smokingrelated cues. The repeated finding in these studies as well as the present study that availability cues that were not previously associated with smoking behaviour can nearly instantaneously acquire the capacity to differentially elicit urge responding provides support for this argument. One could argue, though, that this finding is the result of experimental demand as the participants are instructed beforehand about the predictive meaning of the availability cues and that, hence, they behave according to received instructions rather than learning these contingencies through experience. However, according to contemporary learning theory, human conditioned responding - both subjective and autonomic psychophysiological responding - is based on stimulus-outcome associations that can be acquired through both explicit instructions and trial-by-trial experience (see e.g., Dawson \& Schell, 1987; Davey, 1992; Lovibond, 2003). Furthermore, providing information of the CS-US contingency before the conditioning task elevates conscious awareness of the association between the colour of the serving tray and the (un)availability of smoking hence facilitating conditioning (see e.g., Dawson \& Schell, 1987; Field \& Duka, 2001). Nevertheless, one could still argue that participants may have had certain pre-experimental beliefs concerning the outcome of the experiment that led to experimental demand. However, experimental evidence indicates that the present procedure is not sensitive to such demand. Dols et al. (2002) found that a belief-neutralization procedure (given to half of the subjects prior to participation in the experiment) did not fundamentally affect results, that is, irrespective of beliefneutralization participants reported stronger urges when exposed to the availability cue than when exposed to the unavailability cue. As the present experimental procedure is similar to the procedure employed by Dols et al. (2002) it is unlikely that experimental demand played an important role in the present findings.

It should be noted though that the participants in the present experiment were mainly smokers with a low level of smoking dependence and who had no intention to quit smoking at the time of testing. This raises the question whether more dependent smokers would respond to contextual cues in the same manner. Therefore, the data of the five more heavy dependent smokers (i.e., smoking more than 20 cigarettes/day) of this sample were examined more closely. They showed differential urge responding to the availability cues (acquisition; mean difference urge scores $=6.9$ ) and a decrease in urge responding to the availability cue (mean urge on last acquisition trial $=61$; mean urge on last extinction trial $=43.2$ ). At test they still showed differential urge responding to the availability cues (mean difference $=8.5$ ), but only in the acquisition context suggesting renewal.

Summarized, the data presented here suggest that cue-elicited urges to smoke, which are subsequently extinguished in another context, are renewed when participants are exposed to cues in the context in which they had initially learned the association between these cues and smoking. Future research should investigate whether the found renewal of cue-elicited smoking urges generalizes to individuals who receive cue exposure treatment for their smoking addiction, and whether the findings of the present experiment also apply to a sample of more heavy smokers. Nonetheless, the present results do offer support for the context-dependency of extinction that might explain the limited efficacy of cue exposure therapy.

\section{Acknowledgement}

This research was supported by Grant 985-10-006 from NWO-ZON program addiction.

\section{References}

Bouton, M. E. (1988). Context and ambiguity in the extinction of emotional learning: Implications for exposure therapy. Behaviour Research and Therapy, 26, 137-149.

Bouton, M. E. (2000). A learning theory perspective on lapse, relapse, and the maintenance of behavior change. Health Psychology, 19(Suppl. 1), 57-63. 
Brandon, T. H., Piasecki, T. M., Quinn, E. P., \& Baker, T. B. (1995). Cue exposure treatment in nicotine dependence. In D. C. Drummond, S. T. Tiffany, S. Glautier, \& B. Remington (Eds.), Addictive behaviour: Cue exposure theory and practice (pp. 211-227). New York: Wiley.

Carter, B. L., \& Tiffany, S. T. (2001). The cue-availability paradigm: The effects of cigarette availability on cue reactivity in smokers. Experimental and Clinical Psychopharmacology, 9, 183-190.

Collins, B. N., \& Brandon, T. H. (2002). Effects of extinction context and retrieval cues on alcohol cue reactivity among non-alcoholic drinkers. Journal of Consulting and Clinical Psychology, 70, 390-397.

Conklin, C. A., \& Tiffany, S. T. (2002). Applying extinction research and theory to cue-exposure addiction treatments. Addiction, 97, $155-167$.

Davey, G. C. L. (1992). Classical conditioning and the acquisition of human fears and phobias: A review and synthesis of the literature. Advances in Behaviour Research and Therapy, 14, 29-66.

Dawson, M. E., \& Schell, A. M. (1987). Human autonomic and skeletal classical conditioning: The role of conscious cognitive factors. In G. C. L. Davey (Ed.), Cognitive processes and Pavlovian conditioning in humans (pp. 27-55). Chichester: Wiley.

Dols, M., Van den Hout, M., Kindt, M., \& Willems, B. (2002). The urge to smoke depends on the expectation of smoking. Addiction, 97, 87-93.

Dols, M., Willems, B., Van den Hout, M., \& Bittoun, R. (2000). Smokers can learn to influence their urge to smoke. Addictive Behaviors, $25,103-108$.

Drummond, D. C., Tiffany, S. T., Glautier, S., \& Remington, B. (1995). Addictive behaviour: Cue exposure theory and practice. New York: Wiley.

Field, M., \& Duka, T. (2001). Smoking expectancy mediates the conditioned responses to arbitrary smoking cues. Behavioural Pharmacology, 12, 183-194.

Havermans, R. C., \& Jansen, A. T. M. (2003). Increasing the efficacy of cue exposure treatment in preventing relapse of addictive behavior. Addictive Behaviors, 28, 989-994.

Havermans, R. C., Keuker, J., Lataster, T., \& Jansen, A. (2005). Contextual control of extinguished conditioned performance in humans. Learning and Motivation, 36, 1-19.

Heatherton, T. F., Kozlowski, L. T., Frecker, R. C., \& Fagerström, K. O. (1991). The Fagerström test for nicotine dependence: A revision of the Fagerström tolerance questionnaire. British Journal of Addiction, 86, 1119-1127.

Jansen, A. (1998). A learning model of binge eating: Cue reactivity and cue exposure. Behaviour Research and Therapy, 36, $257-272$.

Lovibond, P. F. (2003). Causal beliefs and conditioned responses: Retrospective revaluation induced by experience and instruction. Journal of Experimental Psychology: Learning, Memory, and Cognition, 29, 97-106.

Marlatt, G. A., \& Gordon, J. R. (1985). Relapse prevention: Maintenance strategies in the treatment of addictive behaviors. New York: Guilford Press.

Öst, L. G. (1997). Rapid treatment of specific phobias. In G. Davey (Ed.), Phobias: A handbook of theory, research and treatment (pp. 227-246). Chichester: Wiley.

Thewissen, R., Van den Hout, M., Havermans, R. C., \& Jansen, A. (2005). Context-dependency of cue-elicited urge to smoke. Addiction, 100, 387-396.

Vansteenwegen, D., Hermans, D., Vervliet, B., Francken, G., Beckers, T., Baeyens, F., et al. (2005). Return of fear in a human differential conditioning paradigm caused by a return to the original acquisition context. Behaviour Research and Therapy, 43, 323-336.

Wertz, J. M., \& Sayette, M. A. (2001). A review of the effects of perceived drug use opportunity on self-reported urge. Experimental and Clinical Psychopharmacology, 9, 3-13. 